This is the author's copy of the publication as archived with the DLR's electronic library at http://elib.dlr.de . Please consult the original publication for citation, see e.g.

https://ieeexplore.ieee.org/document/9294323

\title{
System analysis of a high-speed freight train terminal
}

\author{
M. Ehret, M. Böhm, G. Malzacher and A. Popa
}

To achieve the climate protection targets despite the increasing transport demand, the shift from carbon-intensive to more environmentally friendly modes, such as rail, is indispensable in the field of freight transport. The Next Generation Train CARGO concept is intended to improve the competitiveness of rail freight, especially for lowdensity high value goods. However, the corresponding transshipment infrastructure has not yet been analyzed in detail. In this work, we introduce a Model-Based Systems Engineering approach for the closer analysis and specification of an intermodal freight terminal for this high-speed freight train concept. This includes the elaboration of the system idea and context, the most important stakeholders and their requirements as well as the identification of the essential system functions. The systematic approach reveals a broad diversity of stakeholders and points out the complexity of the procedures taking place at the terminal. The chosen approach applied in this work has proven to be promising for the holistic system analysis of an intermodal transport node

\section{Copyright Notice}

(C2020 IEEE. Personal use of this material is permitted. Permission from IEEE must be obtained for all other uses, in any current or future media, including reprinting/republishing this material for advertising or promotional purposes, creating new collective works, for resale or redistribution to servers or lists, or reuse of any copyrighted component of this work in other works.

Ehret, Böhm, Malzacher and Popa, "System analysis of a high-speed freight train terminal," 2020 IEEE 23rd International Conference on Intelligent Transportation Systems (ITSC) Rhodes, Greece. September 20-23, 2020 (Virtual), pp. 3360-3365, doi: 


\title{
System analysis of an intermodal terminal for a high-speed freight train*
}

\author{
M. Ehret, M. Boehm, G. Malzacher and A. Popa
}

\begin{abstract}
To achieve the climate protection targets despite the increasing transport demand, the shift from carbonintensive to more environmentally friendly modes, such as rail, is indispensable in the field of freight transport. The Next Generation Train CARGO concept is intended to improve the competitiveness of rail freight, especially for low-density high value goods. However, the corresponding transshipment infrastructure has not yet been analyzed in detail. In this work, we introduce a Model-Based Systems Engineering approach for the closer analysis and specification of an intermodal freight terminal for this high-speed freight train concept. This includes the elaboration of the system idea and context, the most important stakeholders and their requirements as well as the identification of the essential system functions. The systematic approach reveals a broad diversity of stakeholders and points out the complexity of the procedures taking place at an intermodal terminal. The chosen approach applied in this work has proven to be promising for the holistic system analysis of an intermodal transport node.
\end{abstract}

\section{INTRODUCTION}

The global demand for mobility, both of goods and persons, is expected to rise significantly until 2050 [1]. Regarding the European Union (EU), projections show that a business-as-usual scenario would lead to $\mathrm{CO}_{2}$-emissions approximately one third higher than 1990 levels by 2050, instead of meeting the EU's internal goals [2] or its commitments under the Paris Agreement [3]. In order to meet these commitments and effectively decarbonize the transportation sector, the European Commission has determined that at least $30 \%$ of the total road freight volume should be diverted onto other more energy efficient modes, primarily rail, by 2030 [4]. The rail freight modal share for international traffic inside the EU is steady at around $11 \%$ of current tonne-km [5].

Regarding the overall freight market it is expected that the future growth in Europe is going to be driven by the shipment of Low Density High Value (LDHV) goods [6]. They include semi-finished and finished products, which require flexible and reliable shipment [7]. In general, the transportation of these goods on rail is conducted via Single Wagonload freight (SWL) in the past. In detail, single wagons from different origins are arranged to whole trains for the main run and are separated again into single wagons or wagon groups for the final delivery [8]. However, in the EU LDHV goods are currently being transported by road, as road transportation

*Resreach supported by the Helmholtz Association of German Research Centres on behalf of the Federal Ministry for Economic Affairs and Energy.

M. Ehret, German Aerospace Center (DLR), Institute of System Dynamics and Control, Weßling, Germany (corresponding author to provide phone: +49815328 1741; e-mail: marc.ehret@dlr.de).

M. Boehm, DLR, Institute of Vehicle Concepts, Berlin, Germany (email: mathias.boehm(dlr.de)

G. Malzacher, Stuttgart, DLR, Institute of Vehicle Concepts, Germany (e-mail: gregor.malzacher@dlr.de).

A. Popa, DLR, Institute of Air Transport and Airport Research, Braunschweig, Germany (e-mail: andrei.popa@dlr.de). generally offers shorter transit and lead times, greater flexibility and often lower costs [9]. To increase the share of freight transport on rail the competitiveness of the SWL needs to be improved [10]. This requires new concepts that enable competitive shipment of LDHV goods for rail freight transport [11].

For this reason, the German Aerospace Center (DLR) is developing a highly automated very high-speed train concept called Next Generation Train CARGO (NGT CARGO) [12]. This concept represents a holistic approach for a multiple unit freight train with distributed power, incorporating new technologies allowing a high level of automation for loading, shunting, driving and transshipping of the following potential LDHV goods:

- agricultural products, food and beverage

- textiles, paper and printings

- pharmaceuticals, machinery and equipment

- groupage freight, post and parcels

Besides the identification of potential types of goods, load units and operational scenarios are investigated [13]. NGT CARGO is designed as a double deck high-speed freight train, which consists of self-propelled, autonomous cars which serve the fine distribution to rail sidings and highpowered automated locomotives for high-speed operation of complete train consists serving long distances. In the standard configuration for its maximum operating speed of up to $400 \mathrm{~km} / \mathrm{h}$, the concept consists of 2 aerodynamically designed locomotives and 10 cars for the transportation of euro pallets and small containers.

Since most of the intended consignors and consignees do not have their own railway siding, one key element of the concept is the availability of intermodal operations to cover the first and/or last mile of the shipment on roads [14]. This requires facilities, such as terminals, enabling the transshipment of the goods between rail and other transport modes [15]. In fact, there are a few other concepts and ideas that deal with high-speed rail freight transport, e.g. [16], [17], but there are yet no concrete approaches dealing with intermodal handling systems of smaller transport containers for high-speed rail freight. As discussed in [18] the design of intermodal terminals requires a thorough analysis of the operational context and the derivation of requirements. It is therefore proposed to apply methods of system analysis in order to specify the desired terminal and to derive the design based on the results.

The goal of this work is to analyze and derive the requirements and system functions of an intermodal freight terminal for the NGT high-speed freight train concept. Therefore, the methodology of Model-Based Systems Engineering is used to specify the system. Besides a structured procedure for the analysis, this method uses formalized models allowing for the implementation and 
visualization of complex system interrelationships. Furthermore, these models support the subsequent design process as well as the derivation of simulation models used for the evaluation of performance criteria. Initially, the chosen method is presented. Subsequently, the method is applied for the system analysis of the intermodal terminal. Finally, the results are discussed, summarized and an outlook is given.

\section{Model-BASEd Systems ENGINEERING}

Systems Engineering (SE) is an interdisciplinary and holistic approach that aims to manage the increasing complexity of technical systems within the framework of their design [19]. One of the basic ideas is to emphasize the derivation and specification of requirements based on business analysis and stakeholder needs in order to detect errors in early development phases. By synchronizing and mediating between the different disciplines involved in design, implementation and verification processes, SE aims to keep the entire development in line with the requirements, including costs and schedules. This demands a clear, consistent and transparent documentation of the system specification during the entire life cycle. The methodology of Model-Based System Engineering (MBSE) proposes the application of formalized system models for this task instead of distributing the information in different types of documents and artifacts, such as reports, description documents, lists or verification plans. The main goals of this approach according to [19] are

- $\quad$ improve communication

- increase ability to manage system complexity

- $\quad$ improve quality and knowledge capture

- enhance understanding of SE

The System Modelling Language SysML is a standardized object-oriented language to describe systems specifications in scope of MBSE. It enables the description of system structures, their behavior as well as requirements and to link these specifications consistently to each other [20]. By the use of diverse diagram types, different views of the system can be visualized. Various tools support the use of SysML which are often linked to a specific MBSE methodology, as described in [21]. In this work the Cameo Systems Modeler of MagicDraw and a methodology based on the SYSMOD modelling process described in [20] is applied. The basic steps of the procedure are system analysis and system design. The analysis includes the following substeps:

- $\quad$ Specify system idea and system context

- Stakeholder and requirements analysis

- Use-Case Analysis

During the design process, the system structure and its subsystems are specified by applying a top-down approach based on the analysis results. This includes the verification of each system level regarding the specified requirements.

\section{SYSTEM ANALYSIS}

\section{A. System idea and system context}

The deduction of the system idea is the entry point of the system analysis. In this step, the top-level goals of the system are defined and the context of the system is analyzed. The central demand of the NGT CARGO high-speed concept is to transport LDHV goods on rail by using existing railway infrastructure including tracks for high-speed and mixed traffic for both passenger- and freight trains. Consequently, the primary task of the terminal is to integrate the NGT CARGO vehicles into existing and future logistics chains for these kinds of shipments. Due to the high requirements regarding transport times, reliability and costs, an effective transshipment between the NGT CARGO vehicles and other modes of transport is vital. In the transport chain therefore, the terminal is the bottleneck which must be addressed so that the speed advantage on the main line is not lost.

By analyzing the system context, persons, institutions or externals systems are detected which interact actively or passively with the terminal. The context in which the terminal operates is shown in the diagram in Figure 1. The essential outcome is that the terminal is the interface of three different categories of external systems. These include logistics management systems, railway operation systems and other modes of transport, such as trucks and vans, or prospective transport systems, e.g. ropeways or drones. In order to guarantee a smooth and reliable transshipment, the terminal needs to synchronize the internal processes according to the incoming and outgoing flow of vehicles and freight. This emphasizes the need for an internal management system that plans the required workflows and communicates with external systems.

\section{B. Stakeholder analysis}

The context analysis is the basis for the identification of stakeholders. These are persons or institutions which are affected by the terminal. The identified stakeholder categories are:

- Users and Operators:

$\begin{array}{cl}\circ & \text { Shippers of potential goods } \\ \circ & \text { Logistics service provider } \\ \circ & \text { Forwarder and carrier (road, rail, other) } \\ \circ & \text { Terminal operator } \\ \circ & \text { Infrastructure operator } \\ & \text { (road, rail, energy, communication) }\end{array}$

- Public:

- Public authorities

(e.g. customs or railway authorities)

○ Communities and associations

- Developer:

- Research and concept design

○ Construction and Developer of Subsystems 


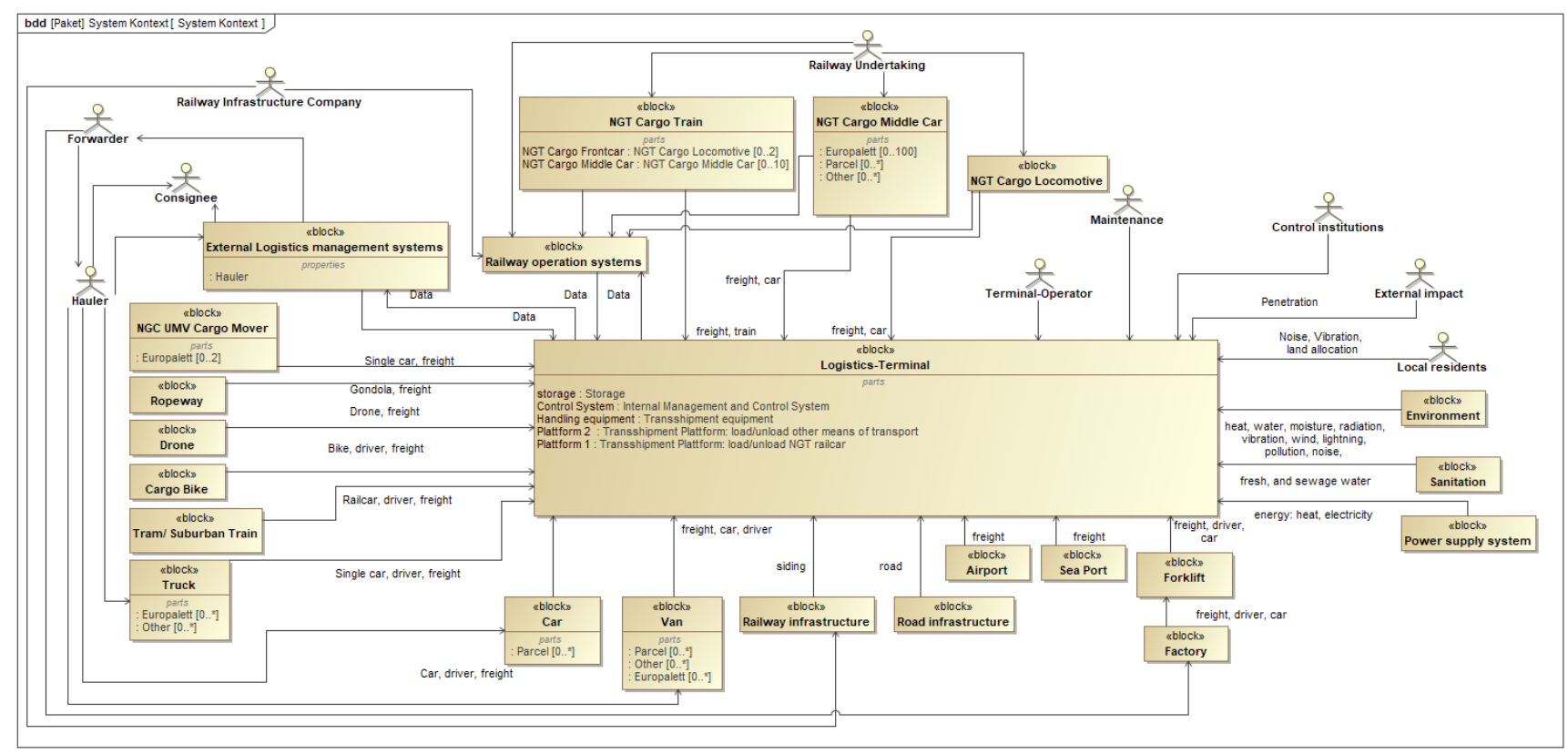

Figure 1. System Context of the Terminal

Each category is decomposed into further subcategories. For presentation purposes only the highest levels are shown in the list. During the development process further stakeholders or actors might be identified, which should be added to the system model.

\section{Requirements analysis}

The identification of requirements starts with the detection of the needs and pain points of the involved stakeholders. Here, we conducted literature research and interviews with representatives of the different categories, focusing on users and operators who primarily determine the concept of the terminal. Subsequently, the needs are translated into stakeholder requirements. These are mapped onto the system requirements for the terminal by assigning them to the categories: functional, usability, reliability, performance, physical and business requirements.

Regarding the transport of potential goods which are intended to be transported by NGT CARGO we found that the basic needs of shippers coincide (namely: reliability, flexibility, predictability, short transportation times, costs and careful handling). However, a closer look yields a broad spectrum of good-specific requirements defining their handling, treatment and logistical processes. In contrast to the other identified potential goods, agricultural products, foods, beverages and pharmaceuticals are subject to strict requirements regarding the compliance of the cold chain. The requirements are in turn dependent on the type of item, e.g. for fruits and vegetables a transport temperature of $3^{\circ} \mathrm{C}-12^{\circ} \mathrm{C}$ is demanded according to [22]. This requires different temperature-controlled storage and transshipment areas in the terminal. To prevent theft and imitations, the storages and transshipment areas of pharmaceuticals additionally need to be equipped with access control and alarm systems [23]. Furthermore, it is found that load units of the potential goods are significantly different in dimensions and weight, in particular for groupage freight and machinery. This leads to varying functional and usability requirements concerning the handling and storing of freight and therefore the degree of automation in the terminal. Except for freight which is transported in fixed load units, such as parcels or beverages on pallets, it is found that the processes taking place at current logistics terminals are mostly performed manually and only supported by semi-automatic loading technology and tracking systems. The findings suggest either reducing the list of potential goods that are handled in the terminal or separating the terminal to certain areas in which similar freight is handled with the same technology and degree of automation.

Since logistic service providers focus on certain types of freight various logistics networks currently exist which already transport the potential goods, e.g. KEP for courier and express freight. Due to the lack of competitive offers by freight rail undertakings, road vehicles (lorries and vans) are almost exclusively the chosen mode of transport. The location of the terminals in the networks is therefore customized to the road infrastructure and the terminals are designed for loading and unloading of road vehicles. If highspeed rail freight is supposed to be a part of the logistics chain in these networks, e.g. the main run, the accessibility of the intermodal terminals for potential haulers is an important criterion. Furthermore, the requirements regarding the transshipment times of the potential goods are extremely short compared to current cargo trains and highly dependent on the logistics network as well as the location of the terminals. Based on interviews with logistic experts, it is assumed that overnight delivery in Germany requires less than one hour of handling at the terminal. In connection with the tight schedules existing for rail infrastructure for mixed traffic and high-speed [24], it becomes clear that the processes taking place at the terminal need to be highly structured and efficient. This requires the planning of incoming and outgoing of vehicles, the allocation and reservation of transshipment areas for all vehicles, the appropriate estimation of transshipment times and storage 
areas as well as reliable tracking and sorting processes. Additionally, it is suggested to refine the operational scenario of the NGT CARGO concept. The results of the requirements analysis reveal to design potential logistic chains based on current transport networks for these types of goods. This includes immerse investigations regarding the optimization of locations for the intermodal terminals.

Overall 50 top-level requirements are identified and documented in the developed system model. However, the list does not claim to be complete. In particular, the identification of performance requirements defining transshipment and storage times and volumes cannot be specified in general, since they strongly depend on the transport relations in question. A possible solution to overcome this problem is a modular composition of the terminal which is scalable to the required performance.

\section{Use-Case analysis}

The functional requirements are refined in the scope of the Use-Case analysis in order to specify the essential functions of the terminal. A Use-Case (UC) describes a specific service provided by a system and is related to one or more actors [20]. We have identified 23 essential UCs, which include tasks dealing with loading and unloading of road and rail vehicles, the management of freight flows and information as well as the shunting of railway vehicles in the terminal system. Some of the UCs linked to the terminal operator are shown in Figure 2. As one can see, UCs may also be linked to external systems, such as the logistics management in case of "Supply Tracking Information". Furthermore, some UCs might contain the same task, e.g. "Monitor freight Condition" in case of "Store Freight" and "Receive Freight". The systematic identification process yields a structured overview of the single tasks that need to be performed by the terminal and identifies redundant functions. In particular, this analysis sharpens the common understanding of the terminal by visualizing and arranging the main functions in the diagram. In doing so, misunderstandings and uncertainties of requirements are detected.

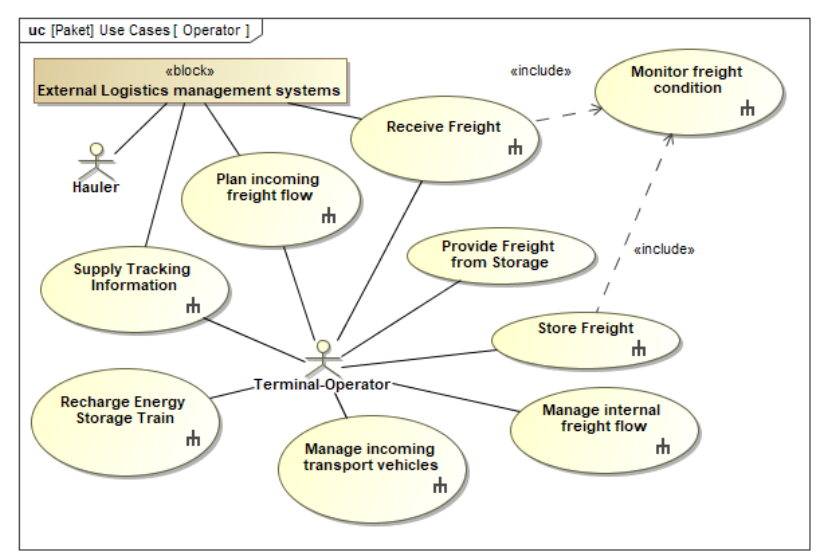

Figure 2. UC-Diagram for the Terminal-Operator

Subsequently, the single steps taking place in each UC are specified by implementing corresponding activities in the system model. These activities describe defined sequences and can contain objects which are generated, passed on or enter and/or leave the procedures. These may be physical items, such as load units or vehicles or information items in form of data. The activity specifying UC "Plan incoming freight flow" is shown in Figure 3. The procedure consists of two steps "Logistics Service Request" and "Assign and Reserve Storage and Transshipment Area", whereby several objects are entering and leaving the activity. For instance, the "Logistics Service Request" contains information from an external logistics system specifying date, type, volume, transport vehicle and destination of freight that will enter the terminal.

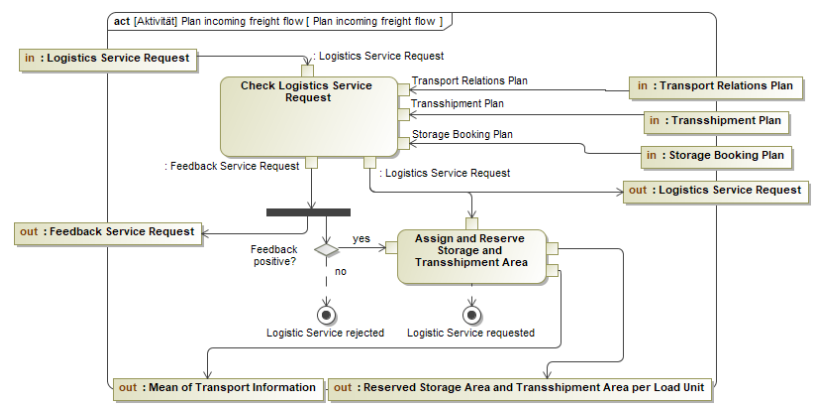

Figure 3. Activity Diagram "Plan incoming freight flow"

The activity diagram in Figure 4 structures the top-level system processes taking place at the terminal. In this diagram the UCs are mapped by corresponding activities, for instance "Manage internal freight flow" located in the center of Figure 4. Taking a closer look one recognizes certain areas in which specific activities and UCs are clustered that are strongly linked to each other. The central part comprises the internal management and procedures which take care of handling, sorting and storing freight. It becomes apparent that a large number of information flows is necessary for the coordination of these internal terminal processes. On the left side processes are clustered dealing with the loading and unloading of road vehicles, whereas on the right side activities linked to railway vehicles occur. Besides loading and unloading, it is necessary to recharge their mobile energy storage as well as to decouple and compose the cars to the NGT CARGO freight train for long distances. The diagram in Figure 4 can be seen as a kind of functional architecture that structures and interconnects the essential system functions by object flows. It allows the description of the terminal independent of the technology and is therefore the final step of the system analysis. The derivation of a physical architecture is the main task of the design process, which is beyond the scope of this paper. It is based on the allocation of logical and subsequently physical components that realize the identified activities.

\section{DISCUSSION}

There are only a few publications investigating intermodal terminals for high-speed rail cargo, e.g. [11], [25] and [26], and none of them applies methods of system analysis to specify the requirements and functions of the terminal. However, they all confirm the need for high-speed freight transport and at the same time they consider the terminal to be an important factor in achieving a competitive intermodal rail service. The results found in the literature are generally consistent with the main requirements of our 


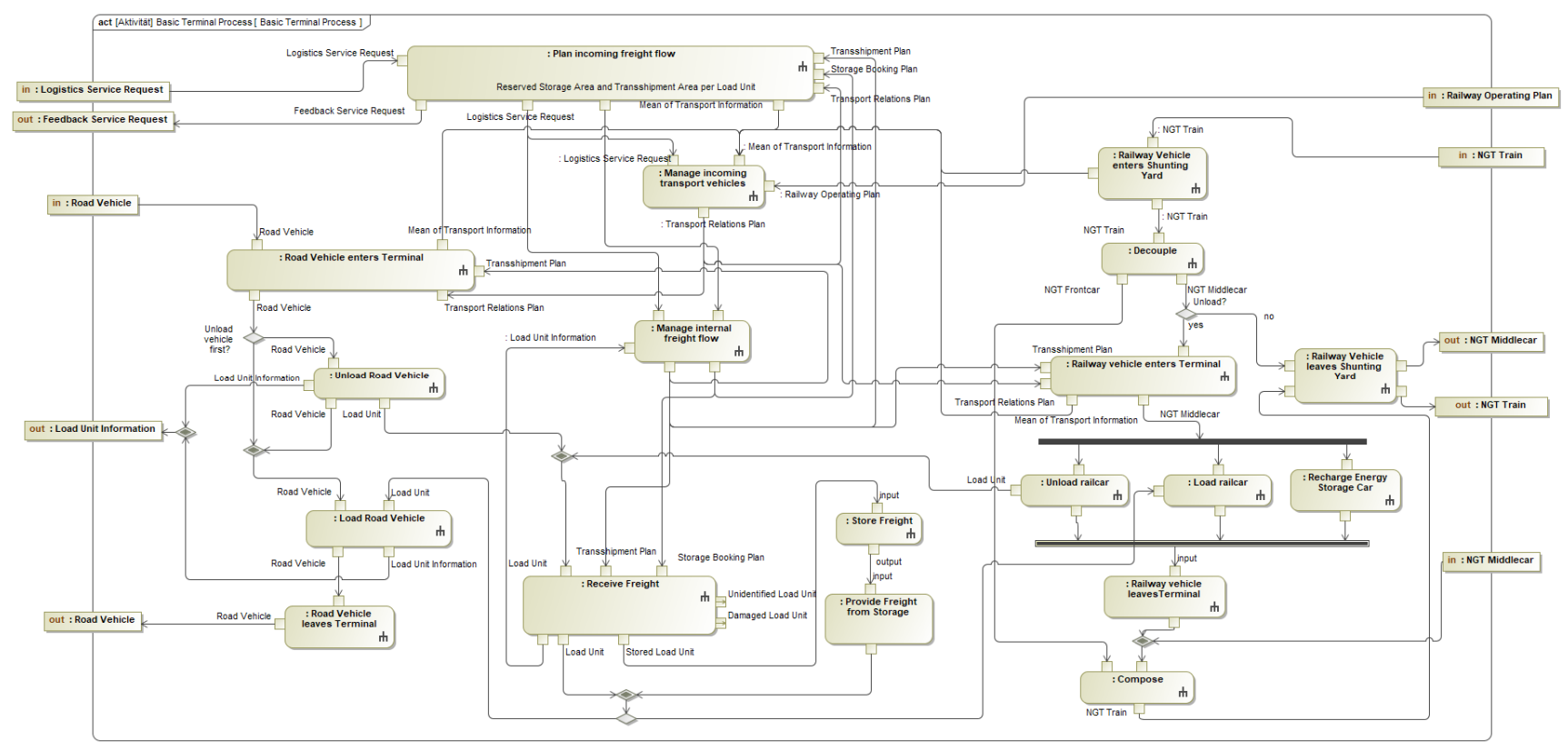

Figure 4. Activity Diagram describing the basic system processes

analysis. For example [11] recommends that technical solutions, such as automated transshipment and temperature controlled systems,

are required for rail freight services for LDHV goods. Furthermore it is found in [11], that these technologies must be complemented by collaborative operational solutions and viable duty scheduling for an intermodal terminal.

The MBSE methodology applied in this work has proven to be promising for the holistic system analysis of an intermodal transport node. The method provides concrete functional requirements based on a systematic approach and additionally enables a consistent documentation. It is found that the identification of stakeholders and the derivation of their needs and pain points are crucial for the development of new freight transport systems. The requirements analysis for the intermodal terminal demanded more effort than expected. Due to the diversity of stakeholders it is difficult to get in touch with representatives of all categories and to find persons, who are open for discussions regarding future transport systems.

The analysis tools, such as system context and use case analysis we use for this work are very helpful methods to broaden the perspective and reveal hidden or not directly obvious system dependencies. A very profitable aspect of these methods is that they can be applied with the participation of several people, which significantly increases the solution space. However, the output strongly depends on the individual expertize of the participants. Furthermore, it has been found that the output of the analyses is enhanced if the meetings are prepared and moderated so that the discussions do not get lost in detail. Besides the documentation of final results in the system model, the use of SysML Diagrams is very helpful to structure the output during the discussions. However, it is expected that the knowledge gained from the system model and the associated diagrams will increase further in the design phase.

\section{CONCLUSION AND OUTLOOK}

To improve the attractiveness of rail freight, a high-speed freight train concept, the Next Generation Train CARGO, was developed in a previous project. However, the corresponding transshipment infrastructure has not yet been analyzed in detail. In this work, we apply the methodology of Model-Based Systems Engineering for the system analysis and specification of an intermodal freight terminal for this concept. The analysis comprises the investigation and specification of

- $\quad$ system idea and system context,

- $\quad$ stakeholders and their requirements as well as

- use-cases.

Initially, the intermodal terminal is identified as a bottleneck in possible logistics chains for LDHV goods based on the NGT cargo concept. As the interface between logistic management systems, railway operation systems and road traffic the terminal needs to synchronize the internal procedures with these external systems to guarantee a competitive logistic chain. The analysis of stakeholders that need to be considered when designing the terminal emphasized the diversity of potential users and operators, including shippers, logistic service providers, railway undertakings and infrastructure companies as well as forwarder and carrier of other modes of transport. The exchange with representatives of logistics service providers clarified the complexity of current logistics chains transporting LDHV goods. Depending on the type of good, various transport networks exist that are adapted to the current road infrastructure. The integration of an intermodal terminal in order to shift the main run from road to rail is therefore linked to high demands concerning accessibility, transshipment times, costs and reliability of the terminal. It is assumed that the transshipment time of freight between road 
and railway vehicles shall not exceed one hour. This demands an internal management system that coordinates all vehicles and freight flows entering and leaving the terminal. Furthermore, immersing investigations regarding the operational concept of NGT CARGO are suggested. Additionally, it turns out that the requirements regarding the transport of goods intended to be forwarded with this concept are differing. This complicates the derivation of transshipment technologies as well as their degree of automation and requires a rethinking of the target goods (as defined in the previous project). Irrespective of the type of freight and operational concept, highly efficient and structured terminal processes are necessary so that the speed advantage on the main line is not lost. Overall we have derived 50 top level requirements subdivided into the categories functionality, usability, performance, physical and business, specifying the terminal. Based on a use case analysis, 23 main tasks were identified that need to take place at the terminal. By interconnecting these tasks with object flows, an example for a functional architecture was deduced. This architecture structures the main functions of the terminal and allows a description of the corresponding activities.

The results found in the literature dealing with the development of intermodal terminals for high-speed rail freight are generally consistent with the main requirements of our analysis. The MBSE methodology applied in this work has proven to be promising for the holistic system analysis of intermodal transport nodes. The method provides concrete functional requirements based on a systematic approach and additionally enables a consistent documentation. It is found that the identification of stakeholders and the derivation of their needs and pain points are crucial for the development of new freight transport systems.

In further investigations the results of the work shall be used as a starting point for the design and verification of the terminal. Based on the identified use cases and the functional architecture, physical elements need to be identified which realize the corresponding activities. In doing so, the functional architecture is transformed into a physical architecture of the terminal. According to the MBSE methodology, the physical components and their interrelations need to be implemented in the system model and related to the functional requirements. In order to verify the physical design based on the identified performance requirements, simulation models shall be derived, which estimate the system behavior with regard to the material flow or technical procedures by means of numerical simulation.

\section{ACKNOWLEDGMENT}

The idea for this work was developed within the DLRproject Next Generation Train and further developed in Transition, founded by the Helmholtz Association of German Research Centres on behalf of the Federal Ministry for Economic Affairs and Energy.

\section{REFERENCES}

[1] ITF, Ed., ITF Transport Outlook 2019, Paris: OECD Publishing, 2019

[2] European Commission, “Energy Roadmap 2050,” Luxembourg, 2012.

[3] United Nations Framework Convention on Climate Change, „Adoption of the Paris Agreement. Report No.
FCCC/CP/2015/L.9/Rev.1““ 2015.

$\mathrm{http} / / / \mathrm{unfccc}$.int/resource/docs/2015/cop21/eng/109r01.pdf.

[4] European Commission, „WHITE PAPER - Roadmap to a Single European Transport Area - Towards a competitive and resource efficient transport system "“ Brussels, 2011.

[5] European Commission, "Statistical Pocketbook - EU Transport in figures," Luxembourg, 2019.

[6] T. Zunder and D. Islam, "Assessment of existing and future rail freight services and Technologies for low Density High Value Goods in Europe," European Transport Research Review, no. 10, pp. https://doi.org/10.1007/s12544-017-0277-1, 2018.

[7] D. Islam, R. Jackson, T. Zunder and A. Burgess, "Assessing the impact of the 2011 EU Transport White Paper - a rail freight demand forecast up to 2050 for the EU 27," European Transport Research Review, no. 7, 2015.

[8] P. Guglielminetti, M. France, D. Artuso, E. Lunadei, A. Musso, G. Fusco, R. Licciardello, C. Piccioni und F. Seno, „Study on Single Wagonload Traffic in Europe - challenges, prospects and policy options," European Commission, Luxemburg, 2014.

[9] S. Gleave, F. Dionori, L. Casullo, S. Ellis, D. Ranghetti, K. Bablinski, C. Vollath and C. Soutra, "Freight on road: Why EU shippers prefer truck to train," European Parliament - Directorate-General for internal policies - Policy Department B - Structural and cohesion policies Transport and Tourism, Brussels, 2015.

[10] U. Clausen and R. Voll, "A comparison of North American and European railway systems," European Transport Research Review, no. 5, pp. 129-133, 2013.

[11] D. Islam and T. Zunder, "Experience of rail intermodal freight transport for low-density high value (LDHV) goods in Europe," European Transport Research Review, no. 10, 2018.

[12] D. Krüger, G. Malzacher, M. Böhm and J. Winter, "NGT CARGO - An intelligent rail freight system for the future," in European Transport Conference (ETC), Barcelona, 04.-06.10.2017.

[13] T. Schumann, M. Moensters und C. J. B. Meirich, ,NGT Cargo Concept For A High-Speed Freight Train In Europe, “ in COMPRAIL 2018, Lissabon, Portugal, 2018.

[14] D. Islam, S. Ricci and B.-L. Nelldal, "How to make modal shift from road to rail possible in the European transport market, as aspired to in the EU Transport White Paper 2011," European Transport Research Review, vol. 8, 2016.

[15] D. Islam, "Barriers to and enablers for European rail freight transport for integrated door-to-door logistics service. Part 2: Enablers to multimodal rail freight transport," Transport Problems, vol. 9, no. 4, pp. 5-13, 2014.

[16] Railway Technology, ,Mercitalia Fast: the world's first high-speed rail freight service," 1501 2019. [Online]. Available: https://www.railway-technology.com/features/mercitalia-fast-service/.

[17] M. Cavagnaro, P. Umiliacchi, G. Fadin, V. Delle Site, ,Innovative freight rail concept for high-speed door-to-door delivery: Hyperfreight," in 12th World Congress on Railway Research, Tokyo, 2019.

[18] J. Woxenius, „Development of small-scale intermodal freight transportation in a systems context, " Dissertation, University of Gothenburg, 1998.

[19] INCOSE, Systems Engineering Handbook, San Diego, CA, USA: Wiley, 2015.

[20] T. Weilkiens, Systems Engineering mit SysML/UML, Heidelberg: dpunkt.Verlag, 2014.

[21] J. A. Estefan, ,Survey of Model-Based Systems Engineering (MBSE) Methodologies, “ INCOSE, Pasadena, California, U.S.A., 2008.

[22] The German Insurance Association (GDV e.V.), ,Transport Information Service," 2020. [Online]. Available: https://www.tisgdv.de/tis e/ware/inhalt.htm/.

[23] D. N. Spiggelkötter, „Der Logistikdienstleister als Pharmalogistiker: Anforderungen, Risiken und Chancen, " in 32. Deutscher LogistikKongress, 2015.

[24] M. Holzhey, ,Rail network 2025 / 2030 Expansion concept for an efficient rail freight service in Germany, " Umweltbundesamt. 2010. http://www.uba.de/uba-info-medien/4005.html

[25] G. Troche, „High-speed rail freight - Sub-report in Efficient train systems for freight transport,“ KTH Railway Group, Stockholm, 2005.

[26] König, Nguyen und Pollehn, ,Schienengüterverkehr in durchgehend elektrischen Lieferketten,“ Eisenbahntechnische Rundschau , pp. 4751, November 2017 